\title{
Rancang Bangun Alat Pengontrol Penyiram Tanaman Otomatis Menggunakan Sensor Kelembaban Tanah Di Area Pertanian
}

\author{
Deddy Prayama $^{1)}$, Amelia Yolanda ${ }^{2}$, Andi Wellyno Pratama ${ }^{3)}$ \\ ${ }^{a}$ Prodi Teknik Komputer, Jurusan Teknologi Informasi, Kampus Politeknik Negeri Padang, Email: deddy@pnp.ac.id \\ ${ }^{2}$ Prodi Teknik Telekomunikasi, Jurusan Teknik Elektro, Kampus Politeknik Negeri Padang, Email: amelia@pnp.ac.id \\ ${ }^{3}$ Prodi Teknik Komputer, Jurusan Teknologi Informasi, Kampus Politeknik Negeri Padang, Email: andiwellyno@yahoo.co.id
}

\begin{abstract}
One of the factors causing the lack of agricultural productivity in Indonesia is the majority of farmers in Indonesia still rely on climate change in the processing of agricultural land. The Design of Automatic Plant Sprinklers Control Devices Using Soil Humidity Sensor in the Agricultural Area was created aimed at helping farmers in Indonesia to manage agricultural land without the need to manually water and see weather conditions. How it works This tool is by using Arduino as a brain movement tool and Soil Moisture Sensor to retrieve data from plants. Then the data that has been obtained by the tool will be sent to the web-based monitoring system using Ethernet Shield. The experimental results and implementation in the field shows that this prototype or prototype can work according to its function and purpose.
\end{abstract}

Keywords: Arduino Uno, Ethernet Shield, Soil Humidity Sensor, Web Based Monitoring System.

\begin{abstract}
Abstrak
Salah satu faktor penyebab kurangnya produktifitas pertanian di Indonesia adalah mayoritas petani di Indonesia masih menggantungkan pada perubahan iklim dalam pengolahan lahan pertanian. Prototype atau purwarupa yang dapat melakukan otomasi penyiraman tanaman ini diciptakan bertujuan untuk membantu petani di Indonesia dalam mengelola lahan pertanian tanpa perlu melakukan penyiraman secara manual dan melihat kondisi cuaca. Cara kerja Alat ini yaitu dengan menggunakan Arduino sebagai otak pergerakan alat dan Sensor Kelembaban Tanah untuk mengambil data dari tanaman. Kemudian data yang telah didapat oleh alat tersebut akan dikirim ke sistem monitoring berbasis website menggunakan Ethernet Shield. Hasil percobaan dan implementasi dilapangan menunjukkan bahwa prototype atau purwarupa ini dapat bekerja sesuai fungsi dan tujuannya.
\end{abstract}

Kata kunci: Arduino, Ethernet Shield, Sensor Kelembaban Tanah, Sistem Monitoring Berbasis Website.

(C) 2018 Jurnal RESTI

\section{Pendahuluan}

Pertanian merupakan tulang punggung pasokan pangan bagi kehidupan bangsa Indonesia[1]. Pemerintah Indonesia terus-menerus berupaya agar pertanian di Indonesia lebih produktif, bila sumberdaya lahan, tenaga kerja, serta sumberdaya lainnya dapat memberikan hasil yang lebih tinggi, maka Indonesia akan dapat menghasilkan bahan pangan yang lebih banyak serta meningkatkan pendapatan masyarakat pedesaan[2].

Salah satu faktor penyebab kurangnya produktifitas pertanian di Indonesia adalah mayoritas petani di Indonesia masih menggantungkan pada perubahan iklim dalam pengolahan lahan pertanian.

Perubahan iklim berdampak pada pola tanam oleh petani, misalnya petani mulai bercocok tanam ketika akan memasuki musim hujan. Ketika musim kemarau tiba, lahan pertanian menjadi kekurangan air. Pada musim pancaroba sering muncul hama yang dapat merusak tanaman pertanian [3]. Sebagai contoh penanaman tanaman bayam yang merupakan salah satu jenis sayuran yang populer di masyarakat. Tanaman bayam memerlukan kelembaban tanah antara 200-700 sehingga membutuhkan penyiraman supaya tanah tidak menjadi kering dan membuat daun bayam menjadi layu atau kekurangan unsur air pada musism kemarau.

Penelitian ini bertujuan untuk membantu memudahkan masyarakat desa dalam mengelola lahan pertanian. Maka akan dibuat suatu teknologi alat yang dapat mengukur tingkat kelembaban tanah disekitar daerah pertanian, kemudian jika kelembaban tanah tidak sesuai dengan yang diinginkan oleh tanaman, maka penggerak motor pompa air akan menyirami tanaman tersebut

Diterima Redaksi : 13-11-2018 | Selesai Revisi : 16-12-2018 | Diterbitkan Online : 26-12-2018 
secara otomatis kemudian pada saat proses terjadi maka Ethernet Shield

data pergerakan alat akan dikirim ke sistem monitoring

berbasis website dan itu akan memudahkan masyarakat desa dalam mengelola dan melakukan pengontrolan pada lahan pertanian.

\section{Tinjauan Pustaka}

Perbandingan penelitian yang dilakukan oleh penulis dengan penelitian sebelumnya dapat mengacu pada perbandingan parameter jenis mikrokontroler dan jenis sensor yang digunakan serta jenis tanaman yang menjadi objek penyiraman seperti terlihat pada tabel 1.

Tabel 1. Tabel Penelitian Sebelumnya

\begin{tabular}{|c|c|c|c|}
\hline Judul & $\begin{array}{c}\text { Jenis } \\
\text { Mikro- } \\
\text { kontroler } \\
\end{array}$ & Sensor & $\begin{array}{c}\text { Objek } \\
\text { Penelitian }\end{array}$ \\
\hline $\begin{array}{l}\text { Penerapan logika } \\
\text { fuzzy pada sistem } \\
\text { penyiraman tanaman } \\
\text { otomatis berbasis } \\
\text { mikrokontroler [4] }\end{array}$ & Atmega16 & $\begin{array}{l}\text { Sensor suhu } \\
\text { lm35, sensor } \\
\text { kelembaban } \\
\text { tanah }\end{array}$ & Seledri \\
\hline $\begin{array}{l}\text { Rancang bangun } \\
\text { sistem } \\
\text { penyiraman } \\
\text { tanaman secara } \\
\text { otomatis } \\
\text { menggunakan } \\
\text { sensor suhu lm35 } \\
\text { berbasis } \\
\text { mikrokontroler } \\
\text { Atmega8535 [5] }\end{array}$ & $\begin{array}{l}\text { Atmega } \\
8535\end{array}$ & $\begin{array}{l}\text { Sensor suhu } \\
\operatorname{lm} 35\end{array}$ & $\begin{array}{l}\text { Tanaman } \\
\text { (secara } \\
\text { umum) }\end{array}$ \\
\hline $\begin{array}{l}\text { Rancang bangun } \\
\text { prototype alat } \\
\text { penyiram otomatis } \\
\text { dengan sistem timer rtc } \\
\text { ds } 1307 \text { berbasis } \\
\text { mikrokontroler atmega } \\
16 \text { pada tanaman } \\
\text { aeroponik [6] }\end{array}$ & Atmega 16 & - & $\begin{array}{l}\text { Tanaman } \\
\text { aeroponik }\end{array}$ \\
\hline
\end{tabular}

Dalam pembuatan penelitian ini menggunakan jenis mikrokontroler yaitu arduino uno dengan menggunakan sensor kelembaban tanah sedangkan yang menjadi objek penelitian adalah penanaman sayuran bayam.

\section{Arduino Uno}

Arduino adalah platform hardware dan software yang dapat digunakan oleh penggiat elektronika untuk membuat prototype alat kontroler berbasis mikrokontroller. [8]

Mikrokontroler adalah komputer yang berukuran mikro dalam satu chip IC (integrated circuit) yang terdiri dari processor, memory, dan antarmuka yang bisa di program. [8]

Arduino memilki board mikrokontroler bersifat open source, selain itu dalam board arduino sendiri sudah terdapat loader yang berupa USB sehingga memudahkan untuk melakukan pemograman mikrokontroler.
Ethernet Shield adalah papan sirkuit tambahan yang dipasang diatas arduino. untuk memperluas kemampuan arduino dengan sirkuit untuk terhubung ke router jaringan, menggunakan kabel Ethernet RJ45 yang tersedia secara umum. Proyek arduino dapat berkomunikasi dengan dunia melalui koneksi ini mulai dari mengambil informasi dari internet.[9]

\section{Sensor Kelembaban Tanah}

Moisture sensor adalah sensor kelembaban yang dapat mendeteksi kelembaban dalam tanah. Sensor ini sangat sederhana, tetapi ideal untuk memantau taman kota, atau tingkat air pada tanaman pekarangan.

Sensor ini dapat mengukur tingkat kebasahan tanah. Kegunaannya misalnya untuk memantau media tanah untuk tanaman.[10]

Sensor ini terdiri dua probe untuk melewatkan arus melalui tanah, kemudian membaca resistansinya untuk mendapatkan nilai tingkat kelembaban. Semakin banyak air membuat tanah lebih mudah menghantarkan listrik (resistansi kecil), sedangkan tanah yang kering sangat sulit menghantarkan listrik (resistansi besar).

\section{Relay}

Relay adalah saklar (Switch) yang dioperasikan secara listrik dan merupakan komponen Electromechanical (Elektromrkanikal) yang terdiri dari 2 bagian utama yakni Elektromagnet (Coil) dan Mekanikal (Seperangkat kontak saklar/switch).

Relay menggunakan prinsip Elektromagnetik untuk mengerakkan kontak saklar sehingga dengan arus listrik yang kecil (low power) dapat menghantarkan listrik yang bertegangan lebih tinggi.[11]

\section{Trafo Step-Down}

Trafo Step-Down berfungsi untuk menurunkan tegangan listrik untuk menghasilkan tegangan yang lebih kecil sesuai dengan kebutuhan rangkaian elektronika

\section{Pompa Celup}

Pompa celup bekerja pada tegangan 6-15V, maksimal $18 \mathrm{~V}$ dan bertegangan rata-rata $12 \mathrm{~V}$ dan arus 1,2 amper. Sumber daya minimal 1,5 amper, agar pompa dapat bekerja maksimal walaupun yang terpakai adalah 1,2 amper.

Mampu mengangkat air hingga 5 meter atau lebih (semakin tinggi tegangan maka semakin tinggi air terangkat dan debit maksimum: 840 liter/jam atau 14 liter per menit (untuk aliran horizontal). Panjang kabel 1,5 meter yakni kabel hitam diameter $5,7 \mathrm{~mm}$ yang berisi 3 kabel di dalamnya cocok urus bertegangan 12 volt. 


\section{Metodologi Penelitian}

Berdasarkan tujuan dari penelitian ini, maka penelitian ini merupakan penelitian terapan, terbagi menjadi beberapa tahap pengerjaan yang tertera sebagai berikut:

\subsection{Pengumpulan Data}

a. Studi Literature

Mengumpulkan data dengan cara mengumpulkan jurnal, paper dan bacaan-bacaan sebagai sumber yang berhubungan dengan alat yang akan dibuat seperti mengumpulkan teori tentang cara penggunaan komponen alat yang berhubungan dengan perancangan alat tersebut.

\section{b. Kebutuhan Sistem.}

Langkah ini diperlukan untuk mengetahui kebutuhan hardware dan software yang akan digunakan serta mempelajari mengenai perancangan program sistem alat tersebut.

\subsection{Tahap Perancangan}

Dalam tahapan ini ditentukan beberapa langkah diantaranya : (a) Analisa kebutuhan sistem, dimana dalam langkah ini ditetapkan kebutuhan - kebutuhan sistem terutama kebutuhan perangkat keras untuk dapat mengolah data yang diperoleh sesuai dengan referensi dan kebutuhan sistem yang dilakukan pada tahap pengumpulan data.(b) Pembuatan Alat, dalam tahapan ini di fokuskan pada pembuatan dan pemasangan komponen yang akan digunakan pada alat tersebut.(c) Pembuatan Program, tahapan ini difokuskan pada pembuatan program sesuai dengan perancangan alat yang ada. (d) Implementasi, Tahapan ini merupakan tahapan akhir dari pembuatan sebuah alat. Setelah melakukan semua tahapan diatas, maka alat yang sudah selesai akan diujicobakan cara kerjanya diareal yang ditetapkan dan selanjutnya dikampus Politeknik Negeri Padang dalam bentuk miniatur.

\subsection{Penanaman Sayuran Bayam}

Bayam cocok ditanaman di dataran rendah sampai dataran tinggi. Pertumbuhan dan produksi tanaman dapat mencapai hasil yang maksimal jika dibudidayakan di tempat yang terbuka dengan kondisi tanah yang subur dan gembur, kaya akan bahan organik, memiliki aerasi dan drainase yang baik, serta mempunyai $\mathrm{pH}$ antara 6-7[7]. Pada tanaman bayam memerlukan tingkat kelembaban tanah antara bit 700200.

\subsection{Monitoring Sistem}

Sistem ini dirancang untuk dapat dimonitor secara onsite maupun online. Untuk monitoring berbasis website, PHP dan MySQL adalah tools yang dipergunakan. Data dikirim ke sistem monitoring dalam bentuk informasi suhu dan kelembaban tanah, disertai status penyiraman pompa setiap 3 menit. Data yang diperoleh dari sensor dikirim dari Arduino melalui Ethernet Shield ke server yang disiapkan. Secara garis besar, alur penelitian ini dapat dilihat pada gambar 1.

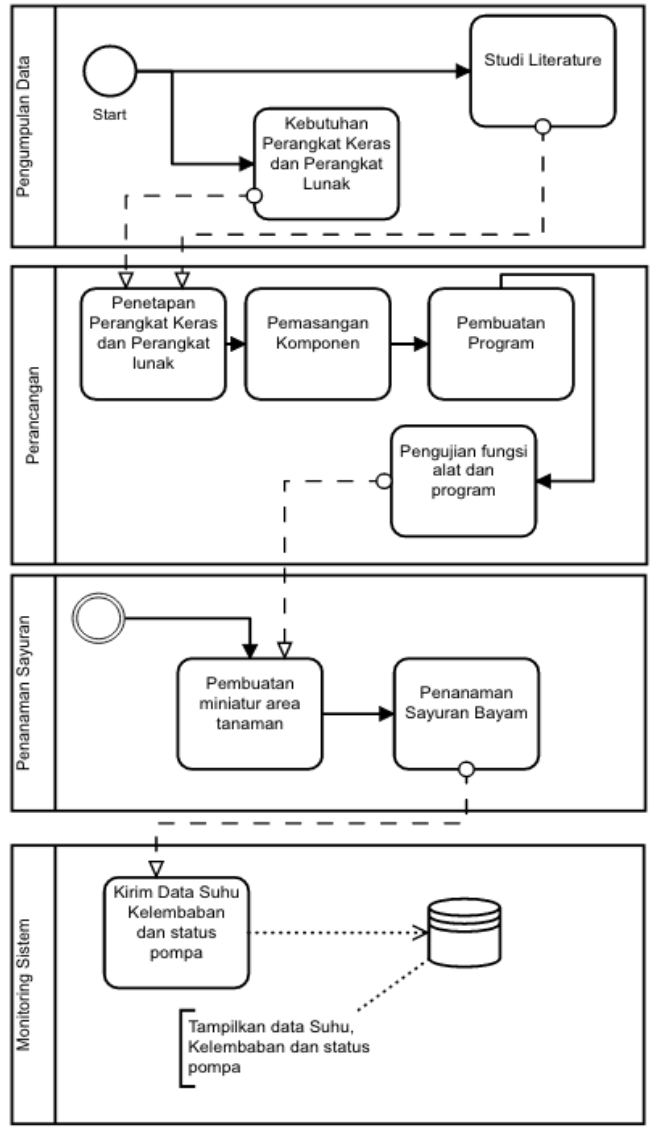

Gambar 1. Alur Penelitian

\section{Perancangan Sistem}

Perancangan sistem dilakukan mulai dari pembentukan alur kerja alat seperti yang terlihat pada gambar 2 .

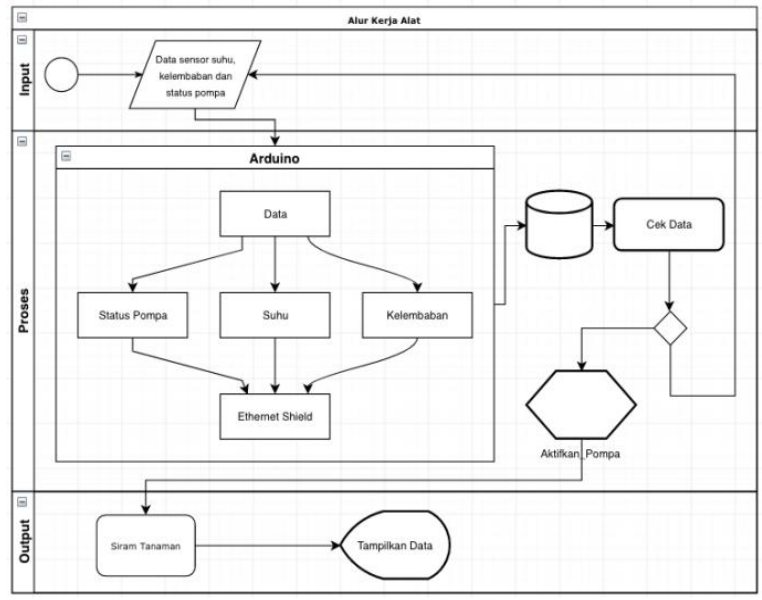

Gambar 2. Alur Kerja Alat 


\section{Blok Diagram Sistem}

Sistem yang akan rancang pada penelitian ini terdiri dari tiga bagian yaitu, bagian otomatis pompa, bagian Arduino dan bagian monitoring.

Bagian pompa secara aktif akan mendapatkan suplay tenaga dari tegangan listrik yang menggunakan sirkuti penyearah untuk diteruskan ke relay.

Arduino yang sudah dilengkapi dengan program dan sensor suhu serta kelembaban, akan menerima input sesuai kondisi sensor. Jika tercapai kondisi tertentu, maka Arduino akan mengirimkan informasi ke relay agar diteruska ke pompa.

Arduino juga senantiasa mengirimkan informasi yang dimiliki ke Database melalui Ethernet shield. Pada bagian ketiga, data yang telah masuk kedatabase ditampilkan melalui web.

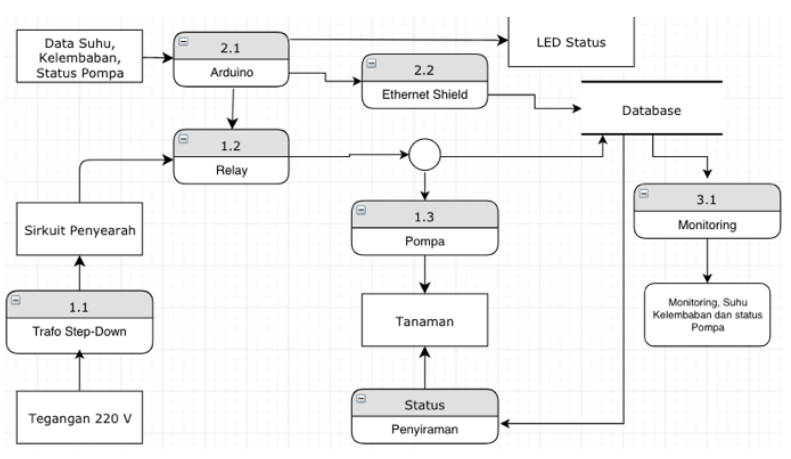

Gambar 3. Blok Diagram Sistem

Papan Sirkuit Untuk Menyearahkan Tegangan Dari AC Ke DC

Papan Sirkuit ini dirancang untuk meyearahkan tegangan yang telah dirubah oleh Trafo Step-Down sehingga menjadi tegangan yang lebih kecil dan dapat digunakan untuk rangkaian elektronika.

Pada papan sirkuit ini terdiri dari beberapa komponen yaitu: (1) Terminal DC yang berguna untuk menginputkan tegangan AC 12 Volt. (2) Dioda yang berguna untuk mengubah tegangan dari 12 Volt AC Menjadi 12 Volt DC. (3) Kapasitor Polar 2200 Mikro Farad yang berguna untuk menyimpan arus listrik dalam bentuk muatan.(4) Kapasitor Keramik 104 Mikro Farad yang berguna untuk menyimpan muatan listrik.(5) Headsink yang berguna untuk membuang panas yang dihasilkan IC.(6) IC yang berguna untuk mengubah tegangan menjadi 12 Volt DC.(7) Kapasitor Polar 470 Mikro Farad yang berguna untuk menyimpan arus listrik dalam bentuk muatan.(8) Resistor 10K Ohm yang berguna untuk mengatur besar kecilnya arus ke LED (penanda ada atau tidak tegangan yang mengalir ke terminal).(9) Terminal DC yang berguna untuk menginput tegangan 12 Volt DC.(10) LED yang berguna untuk sebagai indikator penanda masuk arus atau tidaknya pada papan sirkuit utuk menyearahkan tegangan dari AC ke DC.

Gambar papan sirkuit untuk menyearahkan tegangan dari AC ke DC terlihat pada gambar 5.

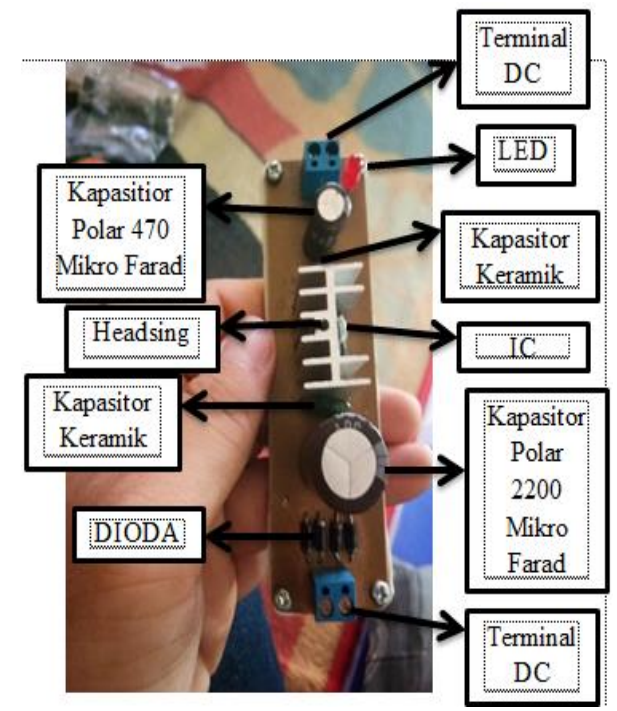

Gambar 5. Papan Sirkuit Penyearah Dari Ac Ke DC

Skema Alat yang dirancang

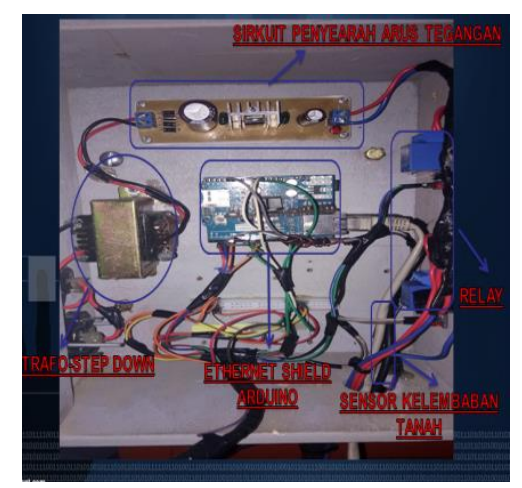

Gambar 6. Skema Perangkat

Dari gambar 6 dapat kita lihat bahwa arus listrik murni sebesar 220 volt diturunkan oleh trafo step-down kemudian arus lisrik murni disearahkan menjadi tegangan arus listrik DC dan diteruskan ke relay yang berfungsi sebagai saklar untuk menghidup dan mematikan pompa secara otomatis.

Ada 3 buah komponen yang terhubung pada arduino yaitu relay, LED, dan sensor kelembaban tanah. Kemudian alat yang telah terhubung ke arduino akan diolah dengan program dan data yang didapat akan dikirim melalui Ethernet Shield ke sistem monitoring berbasis website yang berisi data kelembaban tanah dan pergerakan hidup atau matinya pompa celup untuk melakukan proses penyiraman tanaman secara otomatis. 
Untuk mendapatkan nilai data yang sesuai dengan kondisi kelembaban tanah maka dirancanglah algoritma program sesuai dengan kebutuhan. Dalam hal ini pemograman dilakukan untuk perangkat Arduino Un dimana diperangkat ini juga terlebih dahulu harus waktu

Tabel 2. Tabel Database Data Dari Sensor memiliki library dan dukungan terhadap sensor kelambaban tanah dan Ethernet Shield.

Desain Tampilan Website Monitoring

Tahapan pertama setelah pembacaan library adalah penentuan status dalam hal ini pembacaan nilai sensor kelembaban tanah.

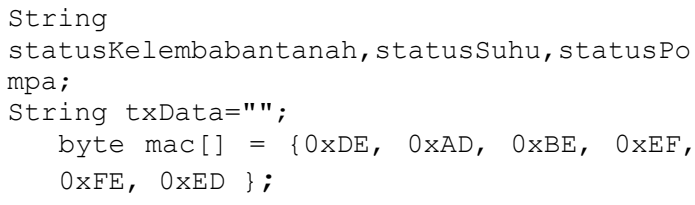

Selanjutnya adalah penentuan alamat atau IP Address dari server.

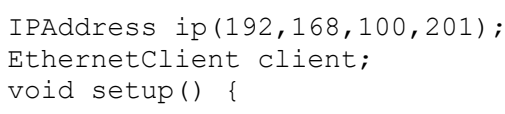

\section{Perancangan Logika Program}

Jika dituangkan dalam bentuk script logika program maka didapatkan hasil dengan menggunakan operasi IF seperti berikut ini :

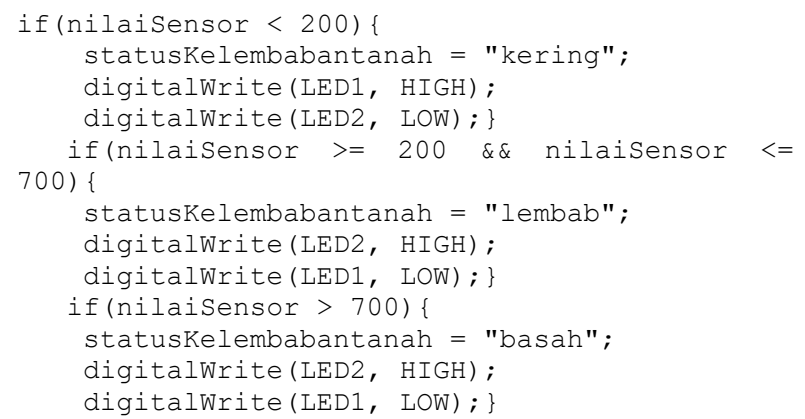

\section{Perancangan Database}

Pada perancangan database untuk memenuhi kebutuhan sistem yang akan dirancang, maka diperlukan susunan database yang terdiri dari beberapa table yang di perlukan sebagai data-data sensor. Pada "tbl_sensor" terdapat 5 (lima) field yaitu field "id" dengan tipe data int, field "kelembaban_tanah" dengan tipe data varchar, field "status_kelembaban_tanah" dengan tipe data varchar, field "kondisi_penyiraman" dengan tipe data varchar, dan yang terakhir field "waktu" dengan tipe data timestamp. Rincian tabel sensor tersebut telihat pada tabel 2.
Dalam pembuatan tampilan website monitoring menggunakan bahasa pemograman PHP dan My SQL sebagai penyimpanan database.

\section{Hasil dan Pembahasan}

Setelah dilakukan perancangan, maka alat dan sistem dapat diimplentasikan untuk dilakukan pengujian alat dan sistem yang telah dirancang tersebut

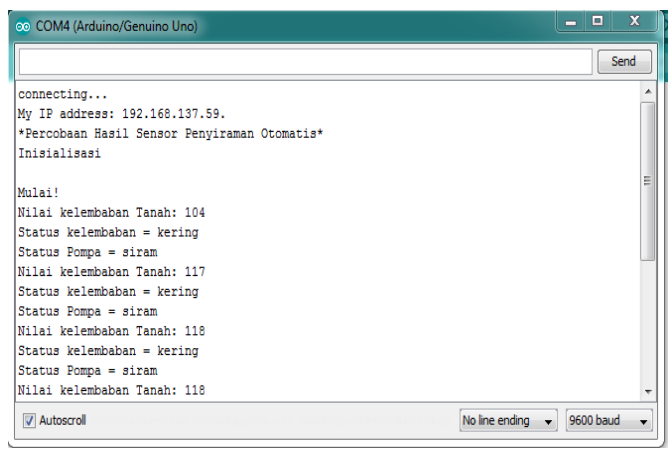

Gambar 7 Hasil Compiler Pada Saat Tanah Kering

Dari gambar 7 dapat dilihat bahwa, algoritma program yang dibuat di arduino dan dapat mengirimkan data dari sensor kelembaban tanah yang diterima untuk diteruskan ke database seperti terlihat pada gambar 8 .

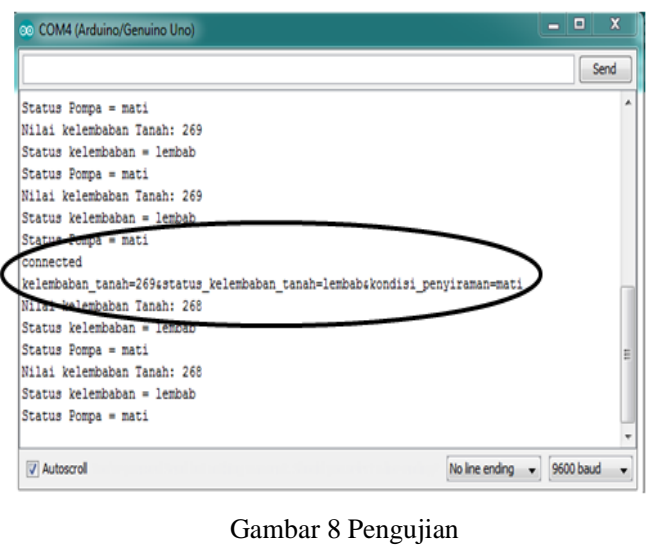

Pada tampilan output alat dapat dilihat pada gambar 9 dan 10.

Setelah proses pada alat selesai dilakukan maka data akan dikirim ke sistem monitoring berbasis website seperti terlihat pada gambar 11 . 


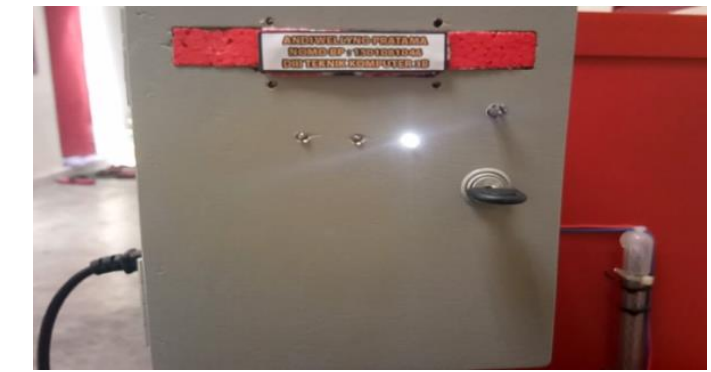

Gambar 9. Kondisi Pada Saat Tanah Lembab Dengan Indikator Lampu LED Berwarna Putih

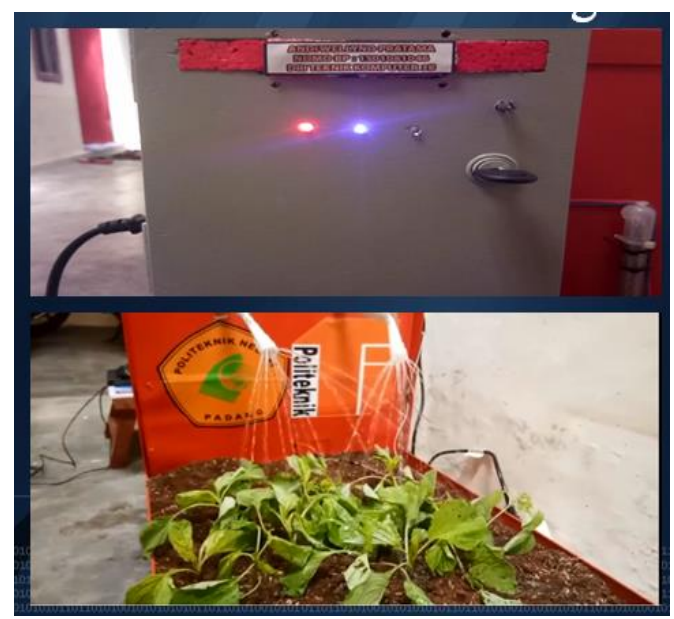

Gambar 10. Kondisi Pada Saat Tanah Kering Dengan Indikator Lampu LED Berwarna Merah Dan Pompa Bergerak Berwarna Biru

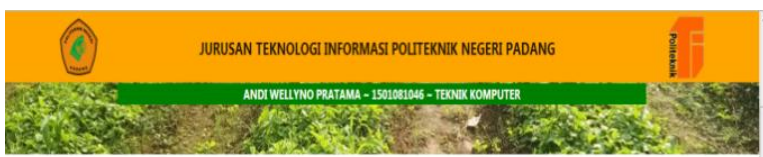

Selamat Datang Di Monitoring Penyiraman Tanaman Otomatis

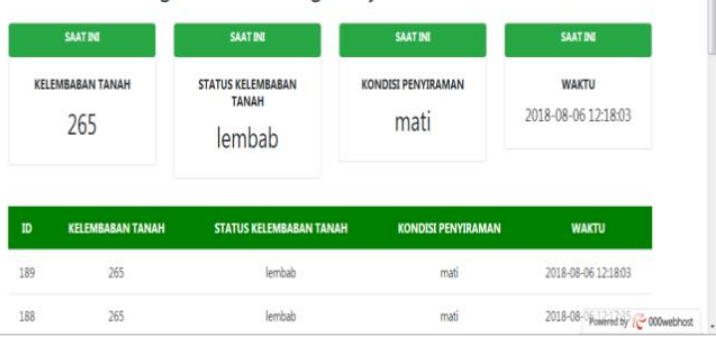

Gambar 11 Tampilan Sistem Monitoring

\section{Analisa Pengujian}

Setelah melakukan pengujian terhadap alat dan sistem yang telah selesai dirancang, maka dapat dilihat bahwa alat yang dilengkapi dengan sensor kelembaban tanah ini dapat bekerja dengan baik dan data yang didapat bisa melakukan eksekusi penyiraman pada tanaman.

Data yang didapat juga bisa melakukan proses monitorng berbasis website sehingga petani dapat memanfaatkan informasi tersebut untuk melakukan tindakan yang diperlukan.

\section{Kesimpulan}

\subsection{Simpulan}

Setelah dilakukan percobaan termasuk implementasi dari alat yang dirancang maka dapat diambil beberapa kesimpulan yaitu:

1. Alat ini dapat bekerja dengan baik sesuai dengan tujuan penelitian ini yaitu menjaga kelembaban tanah pada rentang bit $700-200$

2. Pengujian fungsi pompa dilakukan pada tanaman bayam dan alat dapat menyiram jika ditemui kondisi yang mewajibkan untuk menyiram tanaman.

3. Sistem monitoring berbasis website yang telah dibuat dapat diakses di alamat

3. https://andiwellyno.000webhostapp.com/

\subsection{Saran}

Setelah dilakukan pembuatan alat ini, terdapat beberapa saran untuk pengembangan lebih lanjut, diantaranya :

1. Untuk pengembangan selanjutnya diharapkan dapat menggunakan alat tanpa arus listrik dari PLN karena di lahan pertanian terkadang tidak memiliki sumber arus listrik dari PLN.

2. Alat yang diciptakan ini masih dalam konsep skala kecil menggunakan miniatur dan diharapkan dapat dikembangkan ke area pertanian yang lebih luas.

\section{Daftar Pustaka}

[1] Sunarso(2017) : Strategi Pembangunan Pertanian Yang Visioner \& Integratif. Yogyakarta : Deepublish Publisher

[2] Bahri, Sjaiful dan Pearson, Scott(2005) : Aplikasi Policy Analysis Matrix Pada Pertanian Indonesia .Jakarta : Development Alternatives Inc.

[3] Suherlan, Ade Dan Ananto, Sriwidodo(2013) (Asah Terampil Mandiri) Ilmu Pengetahuan Sosial. Yogyakarta : Grasindo.

[4] T. Pranata, B. Irawan and I.(2015): "Penerapan Logika Fuzzy Pada Sistem Penyiraman Tanaman Otomatis Berbasis Mikrokontroler," Jurnal Coding, Sistem Komputer Untan, vol. III, no. Fakultas MIPA Universitas Tanjungpura.

[5] E. Nasrullah, A. Trisanto and L. Utami(2013 : "Rancang Bangun Sistem Penyiraman Tanaman Secara Otomatis Menggunakan Sensor Suhu Lm35 Berbasis Mikrokontroler ATMega8535," Rekayasa dan Teknologi Elektro, vol. V, no. Teknik Elektro Universitas Lampung.

[6] M. Fadhil, B. D. Argo and Y. Hendrawan(2015): "Rancang Bangun Prototype Alat Penyiram Otomatis dengan Sistem Timer RTC DS1307 BerbasisMikrokontroler Atmega16 pada Tanaman Aeroponik," Keteknikan Pertanian Tropis dan Biosistem, vol. III, no.Fakultas Teknologi Pertanian - Universitas Brawijaya,.

[7] Rukmana, Rahmat H (2005) : Bertanam Sayuran Di Pekarangan. Yogyakarta : KANISIUS

[8] Santoso, Hari(2015) : Panduan Praktis Arduino Untuk Pemula. Malang : ELANGSAKTI.com.

[9] Hammel, Bob(2014) : Connecting Arduino Programming and networking with the ethernet shield. : United States Of America.

[10] Kadir, Abdul(2017) : Pemograman Arduino Dan Processing. Jakarta : PT. Elex Media Komputindo.

[11] Jatmiko, Priyo(2015) : Training Basic PLC. : Kartanagari. 